\title{
ESCUDERO, Eduardo, (2016), Cultura histórica y usos del pa- sado. Memoria, identidades y politica en una experiencia local. (Rio Cuarto; 1947-1986). Rosario: Prohistoria. 342 pp.
}

María Clara Iribarne ${ }^{1}$

El texto de Eduardo Escudero Cultura histórica y usos del pasado. Memorias, identidades y politica en una experiencia local es un trabajo que ofrece múltiples lecturas y algunas claves para pensar los vínculos entre la historia, la memoria y la trama política, en un estudio de caso: la ciudad de Río Cuarto entre 1947 y 1986.

A través de una reconstrucción exhaustiva y minuciosamente documentada de ese marco espacio-tempo$\mathrm{ral}$, el libro recupera debates intensos, actores y conmemoraciones de una ciudad del interior cordobés que en sus diversas intervenciones buscó denodadamente la construcción de una identidad. Pero al mismo tiempo, y en la medida en que transcurre esa narración, es posible sumergirse en la atmósfera cultural en la que estas acciones cobran sentido.

También es un trabajo que se inscribe en la línea pionera abierta por Tcach y Macor en La Invención del peronismo en el interior del pais, quienes advirtieron sobre la necesidad de estudiar los procesos políticos desde una mirada extracéntrica, atendiendo a los contextos de producción de los acontecimientos y recuperando la recepción diferenciada que los mismos suelen tener en el interior del país. En esta perspectiva, el libro avanza en la riqueza de una indagación local, aunque no localista, poniendo de relieve las tensiones y diferencias mantenidas no sólo en clave nacional sino también con la capital provincial.

Eduardo Escudero examina a partir de las colecciones de los periódicos riocuartenses y otras fuentes documentales, como las de la Junta Regional de Historia Argentina de Río Cuarto, lo que denomina «operaciones» de memoria. Apoyándose en el campo de estudios abierto por Pierre Nora y los «usos del pasado» rastrea las intervenciones de distintos actores en la construcción de un imaginario que se vale de la historia como herramienta de legitimación y construcción de hegemonía. Es desde este plano que el libro se divide en dos partes que constituyen dos momentos diferenciados en la elaboración de un relato identitario de la ciudad, que el autor identifica como «dos estaciones memoriales específicas».

La primera parte del libro abarca el periodo que se extiende desde 1947 hasta el derrocamiento de Juan D. Perón. El análisis pone en evidencia los distintos repertorios de las represen-

${ }^{1}$ Doctora en Ciencia Política (Universidad Nacional de Córdoba). Contacto: claireiribarne@gmail.com 
taciones de la historia local, siempre empeñada en construir un lugar protagónico de la historia nacional. La Campaña del Desierto, y la labor de la filial local «José María Paz» del Instituto Nacional Sanmartiniano, movilizaron relatos y discursos profusamente ilustrados por Escudero, en función de construir una épica que era al mismo tiempo pedagógica y política. Sin embargo, el autor no omite la presencia de otras miradas que cohabitaron ese espacio. Las efemérides a Esteban Echeverría en el año 1951 o la conmemoración del centenario del Pronunciamiento de Urquiza durante el mismo año, le permiten constatar la circulación de otras memorias que cohabitaron con el culto sanmartiniano.

El derrocamiento del presidente Perón en 1955 y la destacada participación en el mismo de figuras prominentes de la ciudad -el General Pedro Eugenio Aramburu era nativo de Río Cuarto- se tradujeron durante los primeros años de esa dictadura en remarcar la posición pionera y fundacional de la ciudad en ese acontecimiento. Para el autor, la experiencia de la Revolución Libertadora constituyó una bisagra para la ciudad, que a partir de allí comenzará un proceso de retraimiento en relación a la historia nacional, concentrándose en pensarse en clave local, y al calor de las gestas militares.

La segunda parte del texto se focaliza en la indagación de los distintos proyectos surgidos en la ciudad di- rigidos a encontrar-construir marcas identitarias que posibilitaran legitimar un imaginario de progreso cultural y material. Esta segunda sección analiza también en extenso las prácticas de homenajes y conmemoraciones que reafirmaron una memoria exaltadora de la experiencia militar fronteriza, reafirmando una identidad encarnada en el heroísmo de las gestas militares y a Río Cuarto como enclave decisivo en la defensa contra los indios. Esta operación fue coincidente con $-y$ funcional a- los discursos de la seguridad nacional que irrumpieron en el país a partir de 1966. La importante actividad desplegada por muy diversos actores e instituciones, cristalizaron exitosamente en los discursos tradicionalistas que pueden identificarse aún en la conmemoración del bicentenario en 1986, en plena transición democrática.

El texto de Eduardo Escudero también se detiene en otras experiencias que cohabitaron con las políticas culturales hegemónicas: el grupo Trapalanda de mediados de los años cincuenta y la creación de la Universidad Nacional en los años setenta que contribuyeron a movilizar otras narrativas y preocupaciones en la ciudad.

Cultura histórica y usos del pasado... es un texto minucioso y consistente, que muestra que la indagación sobre espacios locales puede ser fecunda y original abriendo la posibilidad a reflexionar sobre el sentido que revisten las prácticas y los discursos. 